Original article

\title{
Estimation of relatedness in natural populations using highly polymorphic genetic markers
}

\author{
P Capy ${ }^{1, *}$, JFY Brookfield ${ }^{2}$ \\ 1 Centre National de la Recherche Scientifique \\ Laboratoire de Biologie et Génétique Evolutives \\ 91198 Gif sur Yvette Cedex, France; \\ 2 University of Nottingham, Department of Genetics, \\ Queen's Medical Center, Nottingham NG7 2UH, UK
}

(Received 7 May 1990; accepted 2 August 1991)

Summary - This report addresses 3 important questions in population biology: 1), Is it possible to determine the actual kinship between individuals taken at random from a natural population? 2), Is it possible to estimate an average degree of kinship in a population in terms of the probability that 2 individuals drawn at random are related? 3 ), Is it possible to estimate a population's family structure in terms of the number and the relative size of the different families? To answer these questions the estimation of kinship between 2 individuals is first considered. To do this, identity probabilities, based upon 2 sets of assumptions concerning the genetic markers used, were derived for different cases of kinship. The use of VNTRs (variable number of tandem repeats) shows that for multilocus probes, all distributions of identity broadly overlap even when the number of loci is about 20. Therefore by VNTRs alone, it is difficult to define the true kinship between 2 individuals when only their DNA fingerprints are compared. More accurate estimations can be achieved with monolocus probes. However, to estimate a population's structure or the average degree of kinship between individuals, it is not necessary to identify precisely each individual sampled, but rather, only to determine whether individuals are related or not. For this, it is necessary to define a threshold identity value which depends on the common patterns that can be observed between unrelated individuals. Below this value, individuals are considered to be unrelated and, above it, they are considered to be related. Finally, a sequential sampling procedure is proposed.

natural populations / relatedness / genetic marker / multilocus probes / monolocus probes

\footnotetext{
* Correspondence and reprints
} 
Résumé - Estimation de la parenté au sein des populations naturelles à l'aide de marqueurs génétiques hautement polymorphes. Peut-on déterminer les liens de parenté entre 2 individus pris au hasard dans une population naturelle? Peut-on estimer la parenté moyenne, c'est-à-dire la probabilité de tirer au hasard 2 individus apparentés, au sein d'une population naturelle? Ou bien encore peut-on déterminer la structure d'une population, à savoir le nombre et la taille relative des différentes familles qui la composent? Pour répondre à ces questions, l'estimation de la parenté entre 2 individus a été tout d'abord envisagée. A partir de 2 séries d'hypothèses relatives aux marqueurs génétiques utilisés, les probabilités d'identité entre 2 individus ont été définies pour des liens de parenté simples. L'application de ces 2 modèles aux VNTR montre que pour les sondes multilocus, les distributions des probabilités d'identité se recouvrent très largement, même lorsqu'une vingtaine de locus sont détectés. Par conséquent, il est difficile, voire impossible, de déterminer précisément la parenté entre 2 individus en se basant exclusivement sur ce type de données. Par contre, l'utilisation simultanée de plusieurs sondes monolocus permet d'obtenir des estimations plus précises. Pour estimer la structure d'une population ou la parenté moyenne entre individus, il n'est pas nécessaire d'identifier précisément chaque individu, mais uniquement de déterminer si 2 individus sont apparentés ou non. Pour cela, un seuil d'identité est défini en fonction des valeurs d'identité observées entre individus non apparentés. En deçà de cette valeur seuil, les individus ne sont pas considérés comme apparentés et au-delà, il est admis qu'ils le sont. Enfin, une procédure séquentielle d'échantillonnage est proposée.

population naturelle / relation de parenté / marqueur génétique / sonde multilocus / sonde monolocus

\section{INTRODUCTION}

In population genetics many problems of natural populations cannot be solved without a better knowledge of the kinship structure at present and in a small number of generations in the recent past. The effective size of the population, its number of founders and the possible existence of groups of related individuals may be of great importance, but it is usually very difficult to obtain such data or even to make accurate estimates.

For instance, in Drosophila melanogaster, analyses of enzyme polymorphism often show a deficit in heterozygotes in natural populations. The Wright fixation index (Fis) can reach 0.6-0.7 (Danielli and Costa, 1977; David et al, 1989; Vouidibio et al, 1989). Several hypotheses are frequently proposed to explain such results: selection against heterozygotes, inbreeding, and/or the mixing of populations with different allelic frequencies (Wahlund effect). However, it remains difficult to determine the relative importance of each process. Indeed, in Drosophila species, it is almost impossible to estimate the size, the geographical limits and the kinship structure (number of groups of related individuals or families) of a population.

During the last few years, new techniques have been developed for estimates of relatedness between two individuals chosen from a natural population. These techniques rest upon the detection of highly polymorphic DNA sequences, such as minisatellites (Jeffreys et al, 1985). Depending on the species being studied, 
the main problem lies in finding a highly polymorphic system or a combination of systems. The principal characteristic of these systems must allow the definition, for each individual, of a "genetic identity card", or a fingerprint, sufficiently accurate to avoid 2 unrelated individuals possessing the same pattern.

Such genetic systems exist in numerous vertebrates. One example is the major histocompatibility complex (Dausset, 1958; Vaiman, 1970; Klein, 1987) which determines transplant rejection. This system consists of 4 loci, having an average of 10-20 alleles. However, in several natural populations, strong linkage disequilibria are found (Dausset and Svejgaard, 1977). Thus, the probability that unrelated individuals possess the same haplotype can be high.

For invertebrates, only enzymatic data are presently available. However, these techniques do not detect many alleles. For instance, in Drosophila melanogaster, the Amylase locus has approximately 13 described alleles (Dainou et al, 1987) and is among the most highly polymorphic loci. For other enzymes such as Esterase- 6 and Xanthine dehydrogenase, it is often possible to detect many more alleles, ie between 20 and 30 alleles, when electrophoresis conditions like buffer $\mathrm{pH}$ or gel concentration are modified (Coyne, 1976; Singh et al, 1976; Modiano et al, 1979; Ramshaw et al, 1979; Singh, 1979; Keith, 1983). However, the geographical distribution of the alleles is not homogeneous and it is rare for all the alleles to exist in a single region. In other words, at a given place, unrelated individuals may have similar genotypes. Moreover, this disadvantage is reinforced by the fact that, in a given population, the allele frequencies are far from uniform with generally 1 or 2 frequent alleles and several alleles at low frequencies.

Such problems can be partially avoided when several enzymatic loci are considered together. This solution has already been proposed for paternity determination (Chakraborty et al, 1988), for estimates of relatedness between colonies of social insects (Pamilo and Crozier, 1982; Pamilo, 1984; Queller et al, 1988; Queller and Goodnight, 1989) and between individuals in vertebrates (Schartz and Armitage, 1983; Wilkinson and McCraken, 1985). However, these procedures are not always suitable when the social structures of species are unknown or not accessible.

Recently, several genetic systems, such as transposable elements or minisatellites and more generally RFLPs (Restriction Fragment Length Polymorphisms) have provided new ways of estimating the kinship between individuals and of analysing the structure of relatedness (number of groups of related individuals) in natural populations. However, such systems as minisatellites may still not be accurate enough, and several authors have already stressed the limits of these approaches for the analysis of natural populations (Lynch, 1988; Brookfield, 1989; Lewin, 1989).

The first aim of the present work is to evaluate the difficulties in estimating the kin relationship between 2 individuals accurately when different parameters of a natural population, such as the social structure, the mating system, the ageclasses, the generation turnover, and the existence of overlapping generations among others, are unknown. After a brief presentation of the basic model and a means of measuring the degree of identity between 2 individuals, the distributions of identity probabilities between 2 individuals (using two sets of assumptions concerning the genetic systems used) will be presented for different kin relationship. Then, their application to VNTRs (Variable Number of Tandem Repeats) using both multilocus and monolocus probes will be discussed. Finally, attention will be focussed on the 
estimation of kinship structure, ie, the number and the size of groups of related individuals, and on the estimation of an average kinship level, ie the probability that 2 individuals drawn at random are related, in a population of unknown kinship structure. A sampling procedure based upon the model proposed by Rouault and Capy (1986) and by Capy and Rouault (1987) will be proposed.

\section{MATERIALS AND METHODS}

\section{Basic model and identity between 2 individuals}

Each individual is defined by a set of bands obtained after digestion by a restriction endonuclease(s) of total DNA, hybridisation with a marked nucleic acid probe and autoradiography. The resulting set of bands corresponds to the individual's fingerprint and the segregation of each band is Mendelian.

Identity between 2 individuals can be calculated from the number of shared bands; these bands being identical by state or by descent (Lynch, 1988). The expression proposed by Nei and $\mathrm{Li}$ (1979) will be used. In this, the identity between $a$ and $b$ is:

$$
\mathrm{I}_{\mathrm{ab}}=\frac{2 n_{a b}}{n_{a}+n_{b}}
$$

where $n_{a}$ and $n_{b}$ are the number of bands of individuals $a$ and $b$, and $n_{a b}$ the number of bands shared by $a$ and $b$. This expression, which corresponds to the proportion of bands shared between 2 individuals, varies from 0 (if $a$ and $b$ have no common bands) to 1 (if $a$ and $b$ share all their bands).

\section{Identity and relatedness}

In the previous definition, the value of identity increases with the relatedness of individuals. Table I gives some values of identity for common kinship. For all situations given in this table, it is assumed that parents in Go do not share any band and are heterozygous at all their loci. In these conditions, for a single locus, the comparison between full sibs leads to the definition of 3 classes of identity $0,1 / 2$ and 1 with the respective probabilities $4 / 16,8 / 16$ and $4 / 16$. For the comparison between offspring of a backcross, 4 classes of identity exist $0,1 / 2,2 / 3$ and 1 with the respective probabilities $2 / 16,6 / 16,4 / 16$ and $4 / 16$. From these examples, it is clear that for a given average identity, several kin relationships may exist. For instance, the expected values of identity between parent/offspring and between full-sibs are identical $(I=50 \%)$. The same phenomenon is observed for the expected identities between $\mathrm{F} 2$ individuals (offspring of $\mathrm{F} 1 \times \mathrm{F} 1$ ) or between offspring of a backcross $(I=60.42 \%)$. This result is more conclusive when the distributions of identity are considered (next paragraph). 
Table I. Expected values of identity between two individuals for simple kinship relations. In all these situations, it is assumed that parents in $\mathrm{G}_{0}$ do not share any band and are heterozygous at all their loci

\begin{tabular}{lc}
\hline Kin relationship & $\begin{array}{c}\text { Expected identity } \\
(\%)\end{array}$ \\
\hline$G_{0}-G_{1}$ & \\
$\quad$ Parent-offspring & 50.00 \\
$G_{1} \quad$ & 50.00 \\
$\quad$ Full-sibs & 25.00 \\
$\quad$ Half-sibs & 60.42 \\
$G_{2}$ Offspring of a backcross & 60.42 \\
Offspring of $\mathrm{F}_{1} \times \mathrm{F}_{1}\left(\mathrm{~F}_{2}\right)$ & 12.50 \\
First cousins & 25.00 \\
Double cousins & \\
\hline
\end{tabular}

\section{RESULTS}

\section{Expressions and distributions of identity probabilities}

Two simple models will be considered, each of them corresponding to 2 different genetic markers and 2 levels of polymorphism detection. As discussion will be in terms of the application to VNTRs, model I is related to a monolocus system and model II to a multilocus system. In both cases, to simplify the presentation, the existence of an identity by state will be neglected. Expressions for the probabilities and distributions of identity will be given for 4 kinships ie parent/offspring, fullsibs, half-sibs and unrelated individuals. Furthermore, the distribution of identity between F1 individuals of a population, founded by 4 unrelated individuals ( 2 males and 2 females), will be calculated. Finally, in the second model, to illustrate the problem posed by overlapping generations, identities for 4 other kinships (grandparent/grandchildren, uncle/nephew, cousins and double cousins) will be defined.

\section{Model I}

This model corresponds to an idealized situation. It is assumed that: 1), all loci present in a genome, for a given probe, are detected; 2 ), all individuals have the same number of loci $(n)$ and all loci are heterozygous (so that all individuals have $2 n$ bands); 3 ), 2 unrelated individuals do not share any bands.

Under this model, the probability that 2 individuals share $i$ bands according to their kinship, is:

Parent/offspring $(p o)$ :

$$
P_{p_{o(i)}}=1, \text { for } i=n / 2 \text { and } P_{p o}(i)=0 \text { for } i \neq n / 2
$$

Full-sibs $(f s)$ :

$$
P_{f s(i)}=\frac{C_{2 n}^{i}}{2^{2 n}}, \text { with } 0 \leq i \leq 2 n
$$


where $C_{2 n}^{i}$ is the number of combinations of $i$ bands among $2 n$ bands;

Half-sibs $(h s)$ :

$$
P_{h s(i)}=\frac{C_{n}^{i}}{2^{n}}, \text { with } 0 \leq i \leq n
$$

Unrelated individuals $(n r)$ :

$$
P_{n r}(i)=1, \text { for } i=0 \text { and } P_{n r_{(i)}}=0 \text { for } i \neq 0
$$

The probability of sharing $i$ bands if the 2 individuals ( $a$ and $b$ ) compared are derived from the first generation of a population founded by $F$ females and $M$ males, is given by:

$$
P_{a b(i)}=P 0 \cdot P_{n r(i)}+P 1 \cdot P_{h s(i)}+P 2 \cdot P_{f s(i)}
$$

where $P 0, P 1$ and $P 2$ are the probabilities of drawing 2 individuals that are, respectively, unrelated, half-sibs and full-sibs from the population. Assuming that all females and all males have the same expected number of offspring, the values of these probabilities are :

$$
P 0=\frac{(M-1)(F-1)}{M F}, P 1=\frac{M+F-2}{M F} \text { and } P 2=\frac{1}{M F}
$$

In these expressions it is assumed that a given female can be inseminated by several males and a given male can inseminate several females. When $F / M$ mates per males exist, ie monogamy when $F=M$, these probabilities become:

$$
P 0=1-\frac{1}{M}, P 1=\frac{1}{M}-\frac{1}{F} \text { and } P 2=\frac{1}{F}
$$

According to this model, the relationship between identity $(I)$ and the number of shared bands $(i)$ is:

$$
I_{a b}=\frac{2 i}{4 n}
$$

\section{Model II}

In this second model, it is assumed that: 1), the number of bands per individual is not constant ; 2), not all loci are detected; 3), only one band per locus is detected, $i e$ there are no allelic bands in the fingerprint of a given individual; 4), all loci are heterozygous; 5) 2 unrelated individuals do not share any bands; 6 ), the number of bands per individual follows a Poisson distribution with a mean of $n$.

Under these conditions, the probability that 2 individuals share $i$ bands according to their kin-relationship, is:

Parent-offspring ( $p o$ ):

$$
P_{p o(i)}=\sum_{j=i}^{j=j_{\max }} \frac{C_{j}^{i}}{2^{j}} \cdot P_{(j)}
$$


where $P_{(j)}$ is the probability that a parent has exactly $i$ bands, $e$ is exponential, and where $j_{\max }$ is the highest possible value of $j, i e$, the maximum number of bands for an individual. The probability $P_{(j)}$ is given by:

$$
P_{(j)}=e^{-n} \frac{n^{j}}{j}
$$

Full-sibs $(f s)$ :

$$
P_{f s(i)}=P_{p o(i)}
$$

Half-sibs $(h s)$ :

$$
P_{h s(i)}=\sum_{j=i}^{j=j_{\max }} C_{j}^{i} \frac{3^{j-i}}{4^{j}} \cdot P_{(j)}
$$

Grandparent-grandchildren $(p c)$, uncle/nephew $(u n)$, double-cousins $(d c)$ :

$$
P_{p c(i)}=P_{u n(i)}=P_{d c(i)}=P_{h s(i)}
$$

Cousins $(c o)$ :

$$
P_{c o(i)}=\sum_{j=i}^{j=j_{\max }} C_{j}^{i} \frac{7^{j-i}}{8^{j}} \cdot P_{(j)}
$$

Unrelated individuals $(n r)$ :

$$
P_{n r}(i)=1 \text { for } i=0 \text { and } P_{n r}(i)=0 \text { for } i \neq 0
$$

Finally, if 2 individuals are taken at random in the $\mathrm{F} 1$ generation of a population founded by $F$ females and $M$ males, the probability that they share $i$ bands is given by expression (4). Otherwise, according to this model, the relationship between identity $(I)$ and the number of shared bands $(i)$ is:

$$
I_{a b}=\frac{2 i}{n_{a}+n_{b}}
$$

Figure 1 gives the theoretical distributions of identities for the 2 models and for the first 4 kinship relations described here. It has been assumed that exactly 10 loci (ie exactly 20 bands per individual according to the model I) or an average of 10 loci (ie about 10 bands per individual in the model II) can be detected. It can be seen firstly, that the distributions of full-sibs and of half-sibs are symmetrical in model I and asymmetrical in model II. Secondly, in both cases, the identity distributions for full-sibs and half-sibs broadly overlap. As shown in figure 2, this overlapping decreases as the number of loci increases from 1 to 20 loci. However, it remains 


\section{M回田扈!}
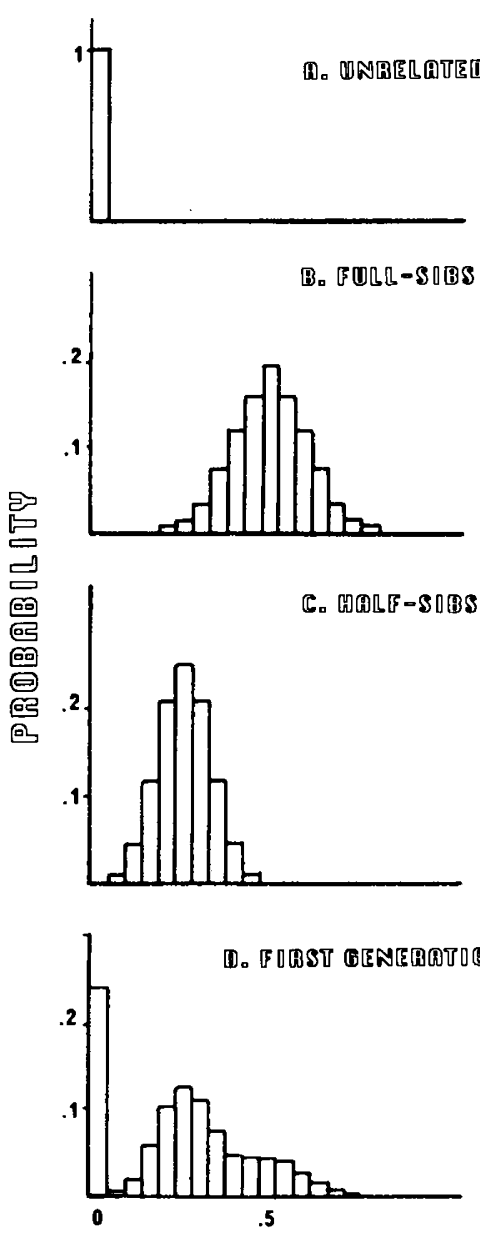

M(D)E[
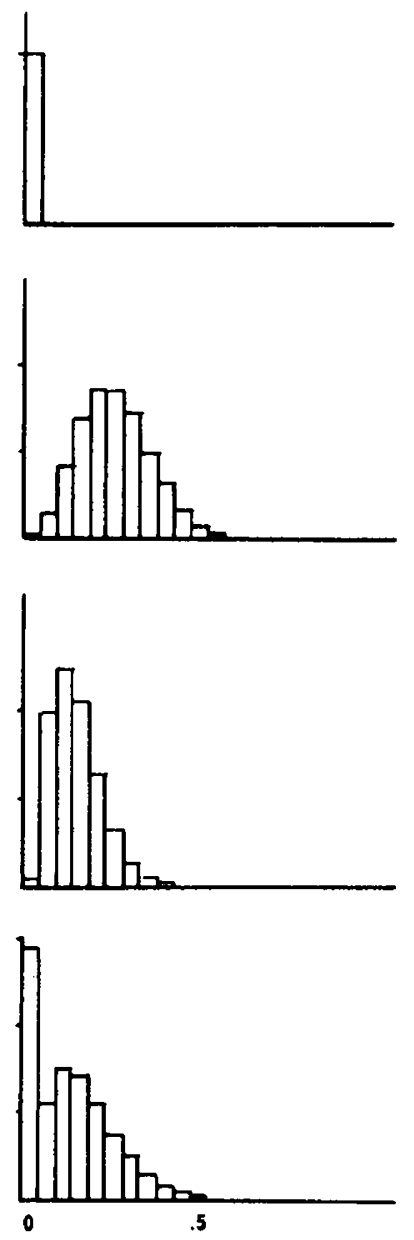

\section{DQENTOT?}

Fig 1. Distributions of identity between 2 individuals when they are: A, unrelated; B, full-sibs; C, half-sibs; D, offspring of a hypothetical population founded by 2 females and 2 males. The formulae for the probabilities are given in the text. For both models, it is assumed that exactly 10 loci (model I) or about 10 loci (model II) can be detected.

difficult to discriminate between the distributions of half-sibs and full-sibs in the F1 progeny of a simple population (see fig 1D).

When successive generations overlap, it becomes more and more difficult to estimate the true kinship between 2 individuals. Indeed, the distributions of parent/offspring, uncle/nephew, grandparent/grandchildren, cousins, and double- 


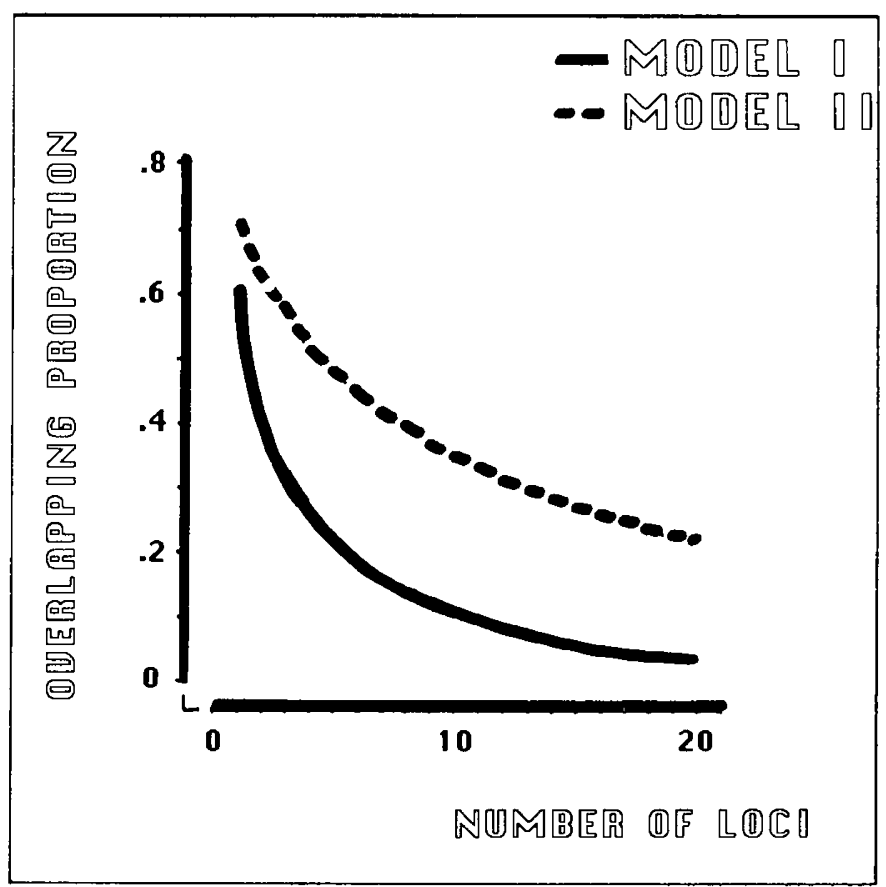

Fig 2. Percentage of overlap between the distributions of full-sibs and half-sibs according to the number of loci considered. The overlapping proportion corresponds to the ratio of the common surface of both distributions over the total surface. The sets of assumptions of the 2 models are given in the text.

cousins must all be considered. Several of these distributions have the same average identity. An illustration of this last problem is given by the analysis of a simple hypothetical genealogy of 3 successive generations (fig 3). In this case, 6 unrelated pairs of grandparents represent the first generation. These pairs each produce between 1 and 4 children. These children (a total of 15 individuals) form the second generation. The third generation is composed of the offspring (a total of 16 individuals) of the couples in the second generation. In this genealogy, 8 kinds or relationship exist and their relative proportions are given in table II. Finally, figure 4 presents the distributions of identities according to model II. Most ot the distributions overlap, making it difficult to determine the exact kin relationship between 2 individuals. For instance, for an identity of 0.25 , the 2 individuals compared can be: full sibs $(3.12 \%)$, half sibs $(2.25 \%)$, uncle/nephew $(35 \%)$, parent/offspring $(3.75 \%)$, grandparent/grand children (43.75\%), first cousins (8.75\%), double cousins (3.38\%).

\section{Application to VNTR loci}

Among the 2 models previously described, the latter seems, a priori, more realistic according to the data obtained with multilocus VNTR probes. Although a different approach has been taken, our conclusions agree with those of Lynch (1989) in 


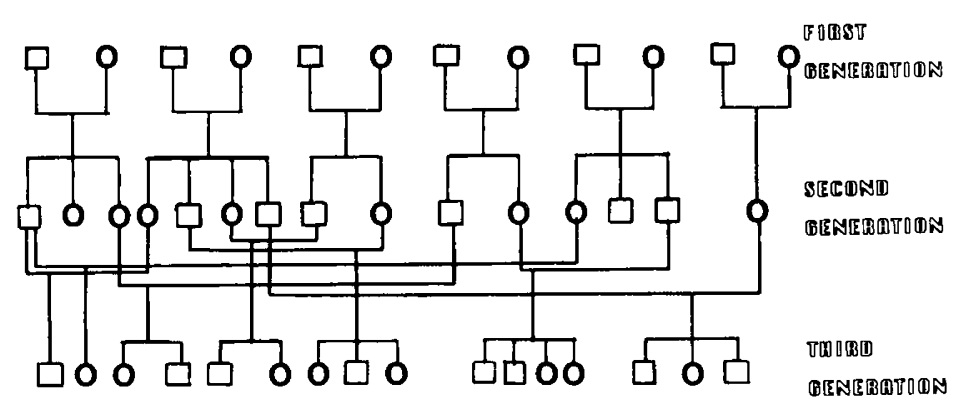

Fig 3. Hypothetical genealogy of 3 successive generations. Eight kinship relations exist. Their frequencies are given in table II.

Table II. Frequencies of the 8 kinship relations of the genealogy given in figure $3 . \mathrm{I}=$ total frequencies; II = frequencies without the class of unrelated individuals.

\begin{tabular}{lrr}
\hline Kin relationship & $I$ & $I I$ \\
\hline Unrelated & 71.65 & - \\
Half-sibs & 0.11 & 0.40 \\
Double cousins & 0.66 & 2.34 \\
Full-sibs & 3.11 & 10.94 \\
First cousins & 4.32 & 15.23 \\
Uncle/nephew & 6.20 & 21.87 \\
Grandparent/grandchildren & 6.87 & 24.22 \\
Parent/offspring & 7.09 & 25.00 \\
\hline
\end{tabular}

pointing out the difficulties in estimating the relatedness between 2 individuals taken at random in a population of unknown structure.

The 2 systems of probes allow one to detect highly polymorphic loci for which the mutation rate can be close to 1/100 per generation and per gamete (Burke, 1989). Thus, the polymorphism (number of alleles) at a given locus should be much greater than that generally observed for an enzymatic locus. In spite of this property, the estimation of the true genetic relationship between 2 individuals remains hazardous with multilocus probes, but seems more accurate with monolocus probes. The primary advantages of monolocus probes are that: 1 ), the number of loci is known; and 2), the homozygous and heterozygous states at a locus can be defined for a given probe (see for example Nakamura et al, 1987).

As regards these advantages, it appears that model I, which was not realistic with respect to multilocus probes, becomes more valid for monolocus probes. Indeed, in this context, if $n$ monolocus probes are used simultaneously, each individual will be defined by a number of bands lying between $n$ and $2 n$, and at least $50 \%$ of these bands will be transmitted to its offspring (table III).

To improve model I, hypothesis 2 can be changed, insofar as it is not necessary to consider that all loci are heterozygous. This is particularly important in small and/or inbred populations in which the frequency of homozygous loci may increase. 


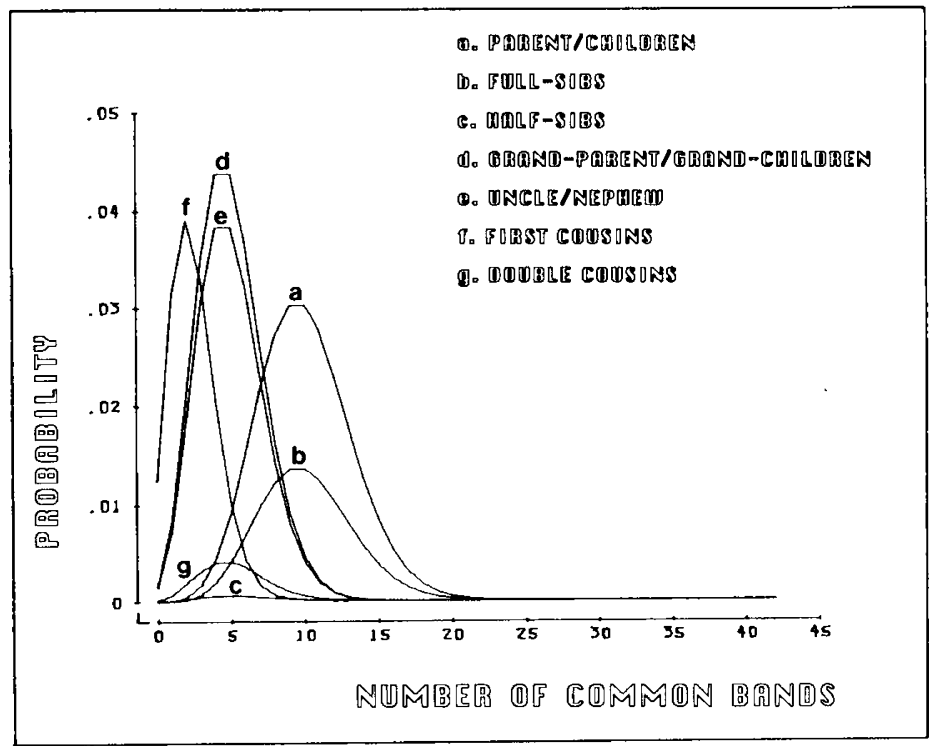

Fig 4. Distributions of identity for the different kinship relations of the hypothetical genealogy presented in figure 3. Distribution corresponding to unrelated individuals ( $71.65 \%$ of the total kin relationship) is not shown. Remaining distributions, between related individuals, are weighted by their relative frequencies (see table II, column II). Expressions of probabilities are given in the text and correspond to the set of assumptions of model II. In this case, the average number of bands per individual is 20 .

Table III. Number of bands transmitted from an individual to its descendants, and variability of identity between parent/offspring and between full-sibs, when monolocus probes are used. $n=$ number of monolocus probes, ie number of loci, $\mathrm{HO}_{1}=$ number of homozygous loci in parent 1 and $\mathrm{HO}_{2}=$ number of homozygous loci in parent 2 . For the identity, its also assumed that 2 parents do not share any band.

\begin{tabular}{lccc}
\hline \multirow{2}{*}{$\begin{array}{l}\text { No of } \\
\text { homozygous loci }\end{array}$} & $\begin{array}{c}\text { No of } \\
\text { transmitted bands }\end{array}$ & \multicolumn{2}{c}{ Identity between: } \\
\cline { 3 - 4 } & $n$ & $50 \%$ & Brother/sister \\
\hline None & $n$ & $2 n$ & from 0 to $100 \%$ \\
$\mathrm{HO}_{1}$ and $\mathrm{HO}_{2}$ & $n$ & $4 n+\mathrm{HO}_{1}$ & from $\frac{\mathrm{HO}_{1}+\mathrm{HO}_{2}}{2 n}$ to $100 \%$ \\
All & $n$ & 66.66 & $100 \%$ \\
\hline
\end{tabular}

Thus, for $n$ monolocus probes, a given individual $(a)$ will present $n a$ bands with $n \leq n a \leq 2 n$. The number of homozygous loci will be $H O=2 n-n a$. In these conditions, the expressions of identity probabilities are identical to those given in model I. Only expressions 2 and 3 must be calculated according to the number of 
heterozygous loci. Thus, if $H O$ represents the average number of homozygous loci per individual in a given population, expressions 2 and 3 become:

Full-sibs $(f s)$ :

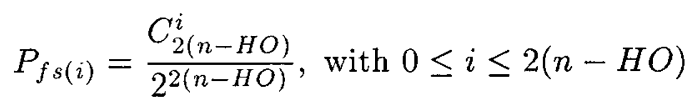

Half-sibs $(h s)$ :

$$
P_{h s(i)}=\frac{C_{n-H O}^{i}}{2^{n-H O}}, \text { with } 0 \leq i \leq n-H O
$$

In these conditions, the total number of shared bands $\mathrm{HO}+i$ will be associated with the above probabilities $P_{f s(i)}$ or $P_{h s(i)}$. The overlapping proportion, between the identity distributions of these 2 kin relationships, will be related to the number of heterozygous loci in their parents. The greater this number, the more the 2 distributions will overlap.

\section{Estimation of the average degree of kinship and of kinship structure}

The previous models are simple cases with some unrealistic assumptions. One assumption is that 2 unrelated individuals do not share any bands. Indeed, Wetton et al (1987) and DT Parkin (personal communication) have shown, using minisatellite sequences, that unrelated birds may share between 10 and $25 \%$ of their bands, which are probably identical in state and not by descent. For minisatellite profiles, this identity can be due to electrophoretic comigration, especially in the upper part of the gel (Lynch, 1988). Two other unrealistic assumptions are that all loci detected are heterozygous and that in a fingerprint there are no allelic bands. For instance, several allelic bands were found in the fingerprint analysis of human families (Jeffreys et al, 1985) in dogs and cats (Jeffreys and Morton, 1987), and in birds (Burke and Bruford, 1987).

Therefore, a more realistic model should consider: 1 ), the number of bands varies from one individual to another; 2), there are homozygous loci and pairs of allelic bands in the fingerprint of an individual ; 3), 2 unrelated individuals may share similar bands identical by state. Under these assumptions, it is obvious that an accurate estimate of kinship between 2 individuals will be even more difficult. This results from the increase in the overlapping proportion of the different distributions of identity, mainly due to identity by state. However, with monolocus probes it seems possible to choose a sample of probes which avoid or minimize these obstacles.

In population genetics, and especially in the analysis of natural population structure, the aim is not always to get accurate estimates of kinship between different individuals (Gilbert et al, 1990; Kuhnlein et al, 1990). In most cases, the purpose is the estimation of the kinship structure. Therefore, it is only necessary to determine whether individuals belong to the same family or not. On the other hand, an identity in state may exist, meaning that 2 unrelated individuals may share some of their bands. In this situation, it becomes necessary to define a threshold value $(T V)$ of identity which will be used to determine whether individuals are related 
or not. Below this value, it will be impossible to determine if two individuals are directly related or share a recent common ancestor, and so they will be considered to be unrelated; above this value, it will be considered that a kinship relation exists between these individuals. Of course, the definition of $T V$ depends upon the polymorphism of the genetic system used and upon the population under study. The more polymorphic the genetic system and the population, the lower the $T V$ will be.

Estimates of the $T V$ can be obtained by comparing known unrelated individuals. For instance, in the work of Wetton et al (1987) on birds, the $T V$ could be chosen between 0.044 and 0.247 (see table I, p 147). However, when nothing is known about the linship structure of the population, the $T V$ can be defined from the identity of individuals belonging to different populations.

If only a fixed $T V$ is defined, errors can be made when identities are very close to the $T V$. For instance, it will be possible to classify as unrelated some related individuals and to classify as related some unrelated individuals. Thus, it will be more correct to define a zone of uncertainty around the $T V$ in which it will be not possible to determine whether 2 individuals are related or not. Of course, the $T V$ and the uncertainty zone will be defined according to the distribution of identity between unrelated individuals. Moreover, with this procedure, only individuals who are directly related (ie parent-offspring, full-sibs, grandparent/grandchildren, etc) will be classed in the same family; and according to the $T V$, first cousins, for whom the expected identity is $12.5 \%$ could be considered as unrelated.

Thus, employing an appropriate $T V$ value, identity can indeed be used just to determine whether individuals are related or not. From an identity matrix, it is then possible to estimate the proportion of pairs of related individuals. This corresponds to the probability, $\mathrm{Pr}$, of drawing at random 2 individuals who share a common ancestor in the recent past, $i e$ in the previous 1 or 2 generations, or who are directly related. Moreover, from the same identity matrix, it is also possible to define different groups of related individuals or families in order to estimate the population structure, $i e$ the number of families and their respective size.

To get accurate estimates of $P r$ and of population structure, a sampling procedure similar to that proposed by Rouault and Capy (1986) and by Capy and Rouault (1987) can be used. This is a sequential procedure based on the relationship between the sample size, the parameter estimated and confidence intervals of proportions and/or a sampling error. In the first case, the proportion of pairs of related individuals must be estimated. The probability of observing $n p$ pairs of related individuals in a sample of $n$ individuals follows a binomial. Since a proportion $(\mathrm{Pr})$ must be estimated, the sampling procedure will be stopped when the confidence interval of $P r$ will be equal to or below a given value fixed $a$ priori before sampling. In the second case, the population structure will be defined by the number and the size of the different groups of related individuals. Thus, the probability of drawing $n i$ members of each family $i$ follows a multinomial distribution. In this latter case, the sampling procedure should be stopped when the probability of the sample and the confidence interval of each proportion (here, the relative proportion of each family) is equal to or below the parameters defined prior to starting to sample (see Capy and Rouault, 1987, for more details). 


\section{DISCUSSION AND CONCLUSIONS}

The above results complement those of Lynch (1988) and Brookfield (1989) and indicate the limits of the use of genetic systems such as minisatellites for the analysis of relatedness in natural populations (see also Lewin, 1989). Nevertheless, as has been shown for birds, such systems may provide new information to complete or confirm that obtained by other techniques (Wetton et al, 1987; Burke,"1989; Burke et al, 1989). Without preliminary data on the structure of the population (size, geographical limit, age-classes, etc) and on the sexual and/or family behavior of individuals, it is quite impossible to estimate the exact kinship relation between different individuals. However, if only the relatedness (without accurate estimates of the true kinship relation) between individuals is considered, it is possible to envisage the estimation of an average rate of kinship or of a population structure. However, with genetic systems which show a high mutation rate and for which it is impossible to detect the kinship between individuals having an identity of $10-15 \%$, the only individuals which can be shown to be related will be parent/offspring, brother-sister, individuals involved in a backcross or, more generally, individuals of inbred strains or families. The main advantage of the model proposed here is that it is not necessary to identify the different alleles and their relative frequencies. However, this can be done for monolocus probes, and in this case a method similar to that proposed by Queller and Goodnight (1989) could be used for estimation of relatedness.

In the present work, only 2 kinds of hypothetical genetic systems have been considered. Among the different systems already described, several could be used for such an analysis. The main characteristics of a suitable system would be the following: (1) each individual has a great number of bands (from 10 to 30); (2) heterozygosity must be high; (3) the number of bands shared by unrelated individuals must be as low as possible.

With regard to the multilocus probes available, most of them do not fulfill all these conditions. The number of bands may vary from 2-3 to more than 20 ; the heterozygosity and the mutation rate seem to be variable but very high (in some cases, $\approx 97 \%$ for the heterozygosity and 0.003 per gamete for the mutation rate; Jeffreys et $a l, 1988$ ) ; but the number of bands shared between unrelated individuals may be large $(\approx 14 \%$ in birds; Wetton et al, 1987).

With the development of monolocus probes, many inconveniences could be avoided or reduced. Several probes could be used simultaneously, as different enzymatic loci, with the advantage that most loci possess a high mutation rate and probably a uniform distribution of their respective alleles in a given population as well. Moreover, with such probes it becomes possible to minimize the level of identity in state between bands of 2 individuals.

\section{ACKNOWLEDGMENTS}

We thank D Krane, DL Hartl, A Larson, M Hedin and 2 anonymous referees for helpful comments. 


\section{REFERENCES}

Burke T (1989) DNA fingerprinting and other methods for the study of mating success. Trends Ecol Evol 5, 139-144

Burke T, Bruford MW (1987) DNA fingerprinting in birds. Nature (Lond) 327, $149-152$

Burke T, Davies NB, Bruford MW, Hatchwell BJ (1989) Parental care and mating behaviour of polyandrous dunnocks Prunella modularis related to paternity by DNA fingerprinting. Nature (Lond) 338, 249-251

Brookfield JFY (1989) Analysis of DNA fingerprinting data in cases of disputed paternity. IMA J Math Appl Med Biol 6, 11-131

Capy P. Rouault J (1987) Estimation of allele number in a natural population by the isofemale line method. Genetics 117, 795-801

Chakraborty R, Meagher TR, Smouse PE (1988) Parentage analysis with genetic markers in natural populations. I. The expected proportion of offspring with unambiguous paternity. Genetics 118, 527-536

Coyne JA (1976) Lack of genetic similarity between two sibling species as revealed by varied techniques. Genetics 84, 593-607

Dainou O, Cariou ML, David JR, Hickey D (1987) Amylase gene duplication: an ancestral trait in the Drosophila melanogaster species subgroup. Heredity 59, 245251

Danielli GA, Costa R (1977) Transient equilibrium at the Est-6 locus in wild population of Drosophila melanogaster. Genetica 47, 37-41

David JR, Alonso-Morraga A, Capy P, Munoz-Serrano A, Vouidibio J (1989) Short range variations and alcohol resources in Drosophila melanogaster. Symp Evolutionary Biology of Transient Unstable Populations (Fontevilla A, ed) SpringerVerlag Berlin, 130-143

Dausset J (1958) Iso-leuco-anticorps. Acta Hematol 20, 156

Dausset J, Svejgaard A (1977) HLA and Diseases. Munksgaard, Copenhagen Gilbert DA, Lehman N, O'Brien SJ, Wayne RK (1990) Genetic fingerprinting reflects population differentiation in the California Channel Island fox. Nature (Lond) 344, 764-767

Jeffreys AJ, Wilson V, Thein SL (1985) Hypervariable "minisatellite" regions in human DNA. Nature (Lond) 314, 67-73

Jeffreys AJ, Morton DB (1987) DNA fingerprints of dogs and cats. Anim Genet 18, $1-15$

Jeffreys AJ, Royle NJ, Wilson V, Wong Z (1988) Spontaneous mutation rates to new length alleles at tandem-repetitive hypervariable loci in human DNA. Nature (Lond) 332, 278-281

Keith TP (1983) Frequency distribution of esterase-5 alleles in two populations of Drosophila pseudoobscura. Genetics 105, 135-155

Klein J (1987) Natural History of the Major Histocompatibility Complex. John Wiley and Sons, New York

Kuhnlein U, Zadworny D, Dawe Y, Fairfull RW, Gavora JS (1990) Assessment of inbreeding by DNA fingerprinting: development of a calibration curve using defined strains of chickens. Genetics 125, 161-165 
Lewin R (1989) Limits to DNA fingerprinting. Science 243, 1549-1551

Lynch M (1988) Estimation of relatedness by DNA fingerprinting. Mol Biol Evol 5, 584-599

Modiano G, Battistuzzi G, Esan GJF, Testa V, Lazzato L (1979) Genetic heterogeneity of "normal" human erythrocyte glucose-6-phosphate dehydrogenase: an electrophoretic polymorphism. Proc Natl Acad Sci USA 76, 852-856

Nakamura Y, Leppert M, O'Connell P, Wolff R, Holm T, Culver M, Martin C, Fujimoto E, Hoff M, Kumlin E, White R (1987) Variable number of tandem repeat (VNTR) markers for human gene mapping. Science 235, 1616-1622

Nei M, Li WH (1979) Mathematical model for studying genetic variation in terms of restriction endonucleases. Proc Natl Acad Sci USA, 76, 5269-5273

Pamilo P (1984) Genotypic correlation and regression in social groups: multiple alleles, multiple loci and subdivided populations. Genetics 107, 307-320

Pamilo P, Crozier RH (1982) Measuring genetic relatedness in natural populations: methodology. Theor Popul Biol 21, 171-193

Queller DC, Strassmann JE, Hughes CR (1988) Genetic relatedness in colonies of tropical wasps with multiple queens. Science 242, 1155-1157

Queller DC, Goodnight KF (1989) Estimating relatedness using genetic markers. Evolution 43, 258-275

Ramshaw JAM, Coyne JA, Lewontin RC (1979) The sensitivity of gel electrophoresis as a detector of genetic variation. Genetics 93, 1019-1037

Rouault J, Capy P (1986) Comment évaluer un nombre de catégories par échantillonnage. Ann Econ Stat 4, 111-124

Singh RS (1979) Genic heterogeneity within electrophoresis "alleles" and the pattern of variation among loci in Drosophila pseudoobscura. Genetics 93, 997-1018 Singh RS, Lewontin RC, Felton AA (1976) Genic heterogeneity within electrophoretic "alleles" of xanthine dehydrogenase in Drosophila pseudoobscura. Genetics 84, 609-629

Schwartz OA, Armitage KB (1983) Problems in the use of genetic similarity to show relatedness. Evolution 37, 417-420

Vaiman M, Renard C, Lafage P, Ameteau J, Nizzu P (1970) Evidence for a histocompatibility system in pig. Transplantation 10, 155-164

Vouidibio J, Capy P, Defaye D, Pla E, Sandrin J, Csink A, David JR (1989) Short range genetic structure of Drosophila melanogaster populations in an Afrotropical urban area, and its significance. Proc Natl Acad Sci USA 86, 8442-8446

Wetton JH, Carter RE, Parkin DT, Walters D (1987) Demographic study of a wild house sparrow population by DNA fingerprinting. Nature (Lond) 327, 147-149 Wilkinson GS, McCraken GF (1985) On estimating relatedness using genetic markers. Evolution 39, 1169-1174 